the Stockholm region, Sweden. It concentrates on the activities of medical teams for first aid, sent to the site of a disaster from one or more of six emergency hospitals within the region. Each team consists of the surgeon and anesthetist on duty and three nurses with special training in emergency medicine, anesthesia or intensive care. The personnel leaving the hospital are replaced by other personnel in the hospital. All members of the team are equipped with special clothing such as an overall and warm underwear, helmet and boots, allowing outdoor work at the low temperatures frequently encountered in the Swedish winter. Doctors and nurses have special markings, so that they are easily recognized.

All members of the teams carry personal medical equipment, adequate to administer first aid to 5 patients, among these 2 seriously injured. It is contained in a belt with four bags and a small rucksack. It is flexible and easily carried by the personnel. In addition, a mobile disaster unit is brought to the scene by the fire service.

\section{CLOSE SUPPORT MANAGEMENT OF MASS CASUALTIES IN COUNTER- TERRORIST OPERATIONS ON AN AIRCRAFT}

\section{T. Michael Moles, M.D., Hong Kong}

Incidents involving large aircraft and hostage seizure by armed terrorists have recently outnumbered major accidents at international airports. Current counter-strategy is to prearrange immobilization of the aircraft at a "friendly" airport pending negotiations. If these fail, or hostage killing forces the issue, the aircraft will have to be stormed by counter-terrorist units, a situation occasioning mass casualties, as occurred in the CAIRO and KARACHI incidents. Planning for such incidents has three special constraints: airports usually have limited life-support resources and capability; they are situated at some distance or time from trauma centers; specialized skills in such operations are unfamiliar and NOT amenable to reasonable training for hospital medical staff. Planning involves: paramedic teams, specially selected, trained and equipped for close support, immediate care, and rescue; hospital-based triage and resuscitation teams deployed to pre-allocated, secure airport locations; appropriate training and resources for immediate life-support management of gunshot, explosive, blast, burns, and smoke inhalation injuries; integration of all services. The establishment, integration and operation of such a system will be described, with illustrative reference to the KARACHI incident.

\section{DISASTER PREPAREDNESS: MUNICIPAL MEDICAL ORGANIZATION AND MANAGEMENT}

\author{
John P. Mariano, B.S. and John W. Becher, Jr., \\ D.O., Philadelphia, Pennsylvania, U.S.A.
}

In order to provide a workable disaster plan and disaster operations to alleviate human suffering and preservation of property, collaboration of the governmental authority and participating private agencies is essential. Various primary health, medical, and related community resources are identified to organize in the development of the plan; suggestions are made for their roles. The following considerations for inclusion in the plan are offered for development by the planner: 1) Cite the authority for its existence. 2) Identify all the governmental jurisdictions and boundaries involved, with a commitment of available resources by each. 3) Cite assumptions for certain conditions under which it might be activated. 4) State a specific mission, purpose, or objective. 5) Include a glossary of key references in the plan. 6) Include a chronological concept of operations with procedures for activation, identification of key field personnel and field operations, a description of a hospital categorization scheme and responsibilities for each, and a complete explanation of the alert phases or various degrees of activation. 7) Attach a directory of all participating government and outside agencies. 8) Guidelines for the administrative and logistical procedures such as procurement and allocation of emergency equipment and supplies, maintenance and preservation of records, modes of communications, and standardized reporting. 9) Emergency personnel identification system, and overall security procedures. 10) Standards for equipment and supplies and guidelines for replenishment. 11) Regular testing, critique, and update of the plan. 